УДК 334.012

\title{
М. М. Стрельник
}

Санкт-Петербургский государственный экономический университет (СПбГЭУ), Санкт-Петербург, e-mail: creative.06@mail.ru

\section{ИСТОЧНИКИ ФИНАНСИРОВАНИЯ КЛАСТЕРА И ЕГО УЧАСТНИКОВ}

Ключевые слова: источники финансирования предприятий, источники финансирования кластера, участники кластера, альтернативные источники финансирования, краудфандинг, краудинвестинг, краудлендинг.

Кластеры относительно новые экономические субъекты многих стран, в том числе и России. В Концепции долгосрочного социально-экономического развития Российской Федерации, утвержденной в 2008 на период до 2020 года, указывалось о необходимости создания кластеров, реализующих конкурентоспособный потенциал территорий, на которых они будут функционировать. В данной статье рассматриваются возможные способы финансирования деятельности кластеров, его участников и возможность привлечения новых дополнительных способы финансирования кластеров в России. Автор систематизирует доступные источники финансирования деятельности кластера и его участников. Собственникам и менеджерам предприятий - участникам кластеров необходимо учитывать допустимые источники финансирования с целью обеспечения необходимого денежного потока, как для текущей деятельности предприятия, так и для реализации проектов предприятия-участника кластера и кластера. В статье приводится сравнение использования альтернативных источников финансирования кластера и его участников: краудфандинг, краудинвестинг, краудлендинг. Принимаемые федеральные законы, регулирующие вопросы использования инвестиционных платформ, цифровых финансовых активов, криптовалюту, позволяют рассматривать возможность применения новых источников и средств финансирования - краудфандинга, криптовалюты и цифровых финансовых активов. Государственное регулирование привлечения инвестиций с применением инвестиционных платформ повышает доверие к краудинговым источникам финансирования в долгосрочном периоде времени и защищает права инвесторов, кредиторов, лиц привлекающих денежные средства.

\section{M. Strelnik}

St. Petersburg State University of Economics (SPbGEU), St. Petersburg, e-mail: creative.06@mail.ru

\section{SOURCES OF CLUSTER AND ITS MEMBERS FINANCING}

Keywords: sources of enterprises financing, sources of cluster financing, cluster members, alternative sources of financing, crowdfunding, crowdinvesting, crowdlending.

Clusters are relatively new economic actors in many countries, including Russia. In the Concept of long-term socio-economic development of the Russian Federation, approved in 2008 for the period up to 2020 , indicated the need of clusters creation realizing the competitive potential of the territories in which they would operate. The possible ways of financing the cluster activity, its members and the ability to attract new additional ways of financing for clusters in Russia are considered in this article. The author systematizes the accessible sources of financing for the activities of cluster and its members. The owners and managers of enterprises - members of clusters must take into account acceptable sources of funding in order to ensure the necessary cash flow, both for the current activities of the enterprise and for the implementation of projects of the enterprise-cluster member and cluster. The article provides a comparison of the use of alternative sources of financing for the cluster and its members: crowdfunding, crowdinvesting, crowdlending. Accepted federal laws regulating the issues of investment platforms using, digital financial assets cryptocurrency, allow to consider the possibility of new sources of funds using - crowdfunding, cryptocurrency and digital financial assets. State regulation of attracting investments using investment platforms increases confidence in crowd sources of financing in the long term period and defends the rights of investors, creditors, entities raising funds.

\section{Введение}

Российские предприятия при финансировании своей операционной, инвестиционной деятельности испытывают трудности с привлечением источников финансирования. По данным Росстата наблюдается устойчивый рост финансирования инвестиций в основной капитал предприятия на основе собственных средств с 50,2\% за 2015 год до 57,1\% за 2020 год [39]. Существуют определенные проблемы с привлечением источ- 
ников финансирования для российских юридических лиц:

- сокращение количества коммерческих банков, что приводит к снижению конкуренции и повышению процентов по кредиту для юридических лиц [11], [12].

- санкции по отношению к России со стороны ЕС и США приводят к ограничению на внешние заимствования российских эмитентов, сокращению притока иностранных инвестиций, увеличению оттока российского капитала [14]. Вследствие введения антироссийских санкций у Российских банков и юридических лиц снижается возможность привлекать средства в Европе, США и иных странах, что негативно влияет на доступность источников финансирования для российских предприятий.

• неэффективный фондовый рынок России по сравнению с фондовыми рынками таких стран как США, Япония, Бразилия [20]. Неэффективность российского фондового рынка в течение долгого периода времени приводит к снижению возможностей для российских предприятий привлекать средства за счет эмиссии ценных бумаг для финансирования операционной и инвестиционной деятельности.

- дефицит государственного бюджета в 2020 году может привести к снижению государственного финансирования национальных проектов [38] и это скажется на финансировании кластерных программ.

Современная экономическая деятельность невозможна без кооперационных связей между предприятиями. В 2008 года была утверждена концепция социально-экономического развития России на период до 2020 года. В данной стратегии указывалась необходимость перехода к кластерному подходу развития экономики, что является новой моделью пространственного развития российской экономики. Ставилась задача создания новых центров социально-экономического развития, которые основывались на развитии энергетической, транспортной инфраструктуры и создания в России сети территориально-производственных кластеров [6].
Согласно проекту Карта кластеров России рост создания кластеров отмечался в 2014 году - 27 кластеров, далее количество вновь создаваемых кластеров уменьшается до двух кластеров, созданных в 2018 году. Всего по данным Карты кластеров России создано 117 кластеров [33]. Кластеры являются одной из форм сетевого взаимодействия предприятий. Для функционирования кластера и реализации конкурентного потенциала необходимо финансирование. Существуют определенные особенности финансирования кластера и его участников.

Цели исследования:

- определить состав кластера;

- систематизировать источники финансирования деятельности кластера и предприятий-участников кластера;

- проанализировать отличительные особенности альтернативных форм финансирования: краудфандинг, краудинвестинг, краудлендинг.

\section{Методы}

В статье применялись следующие методы исследования: анализ, синтез и моделирование. Проводился анализ научных публикаций, посвященных проблемам финансирования деятельности предприятий и реализации кластерных программ. Автор составил модель, отражающую источники финансирования кластера и предприятий-участников кластера.

\section{Результаты исследования и их обсуждение}

Кластер - это совокупность взаимосвязанных, независимых и конкурирующих между собой экономических агентов, осуществляющих различные виды экономической деятельности (как на определенной территории: город, регион, страна - так и на международном уровне) на долгосрочной основе участвующих в цепочке создания ценности кластера [21].

Министерство экономического развития России в 2012 году провело конкурсный отбор пилотных программ инновационных территориальных кластеров для включения победителей данного конкурса в Перечень инновационных территориальных кластеров России [37]. 


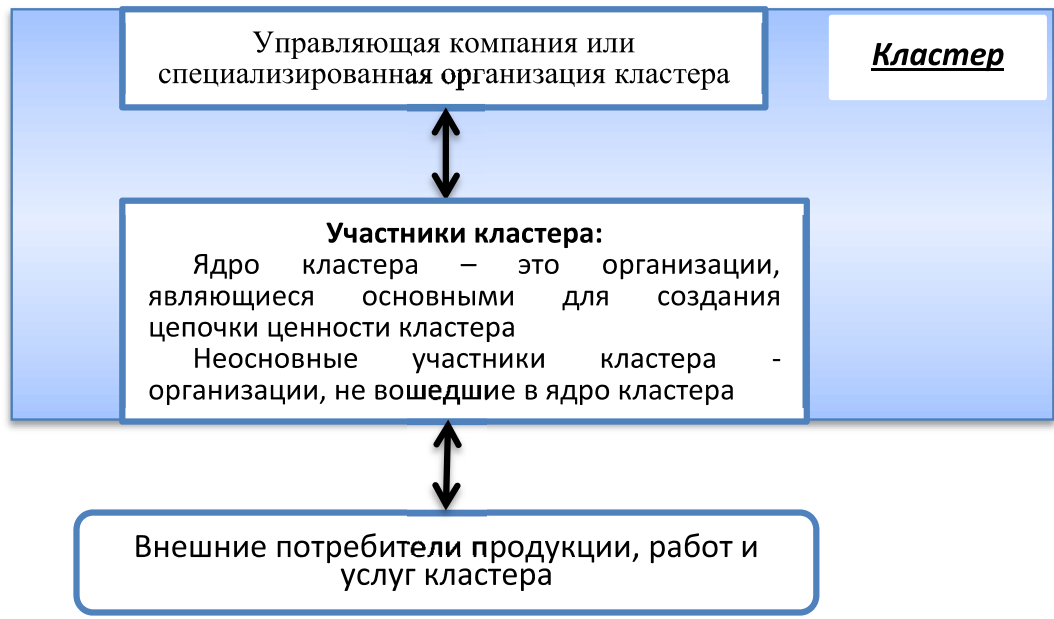

Рис. 1. Состав кластера в России. Источник: автор на основе [13], [16], [28], [30]

В период с 2013 г. по 2015 г. кластерам, которые входили в утвержденную программу поддержки территориальных инновационных кластеров, было выделено 460 млрд. руб., в том числе из бюджетов различных уровней 98 млрд. рублей и 362 млрд. рублей из внебюджетных средств. К 2015 году для поддержки кластеров были созданы 250 объектов, в том числе: центры поддержки малого и среднего предпринимательства в области инноваций и промышленного производства; технопарки; бизнес-инкубаторы; промышленные парки [36]. Государство фактически создавала инфраструктуру и институты, способствующие созданию, поддержки и развитию кластеров в России.

Существует ряд препятствий, связанных с созданием кластеров:

- трудности, связанные с организационной структурой экономического кластера;

- затруднения, связанные с финансированием образования кластеров;

- отсутствие механизмов стимулирования создания кластеров, например налогового стимулирования;

- нет общепринятой методики, позволяющей оценить эффективность функционирования кластеров [15].

Следует отметить, что первоначальное государственное финансирование с целью создания необходимой инфраструктуры, безусловно, являлось существенной помощью для начала функционирования кластеров в России, но это недостаточно в долгосрочном периоде. Необходимо учитывать необходимость привлечения новых источников финансирования операционной деятельности, будущих инвестиционных проектов кластера и участников кластера, помимо средств федерального, регионального и местного бюджетов.

На рисунке 1 представлен состав кластера в России. Субъектами кластера являются участники кластера и управляющая компания или специализированная организация кластера.

Для представления интересов участников кластера и координации их работы создается юридическое лицо, которому передаются функции, направленные на координацию деятельности участников кластера, взаимодействие кластера с внешними агентами (в том числе органами государственной власти) для повышения конкурентоспособности и развития кластера.

В практике закрепилось употребление двух синонимов «управляющая компания» или «специализированная организация» кластера. ${ }^{\text {в } 69 \%}$ случаев функцию управляющей компании выполняют региональные институты развития, которые включают центры кластерного развития, центры поддержки предпринимательства и т.д. [17].

В Постановлении правительства РФ от 31 июля 2015 г. N 779 «О промышленных кластерах и специализированных организациях промышленных кластеров» указывается, что специали- 
зированная организация промышленного кластера может быть учреждена в одной из следующих организационно-правовых формах: автономная некоммерческая организация, ассоциация (союз), хозяйственное товарищество, общество [5].

Состав участников кластера не ограничивается набором конкретных участников (коммерческих и некоммерческих юридических лиц). Участники кластера взаимодействуют друг с другом, осуществляя следующие компоненты деятельности участников кластера:

- производство продукта кластера;

- обеспечение производственного процесса кластера;

- обслуживание (производства и обеспечения производственного процесса кластера);

- исследования и обучение сотрудников кластера;

- экспорт продукции кластера;

- взаимодействие с потребителями продукции, работ и услуг кластера [13].

Участников кластера можно разделить на ядро кластера и организации, не вошедшие в ядро кластера. Ядро кластера - это организации, являющиеся основными для создания цепочки ценности кластера. Организации, которые не входят в ядро кластера, незначительно влияют на цепочку ценности кластера и их выход из кластера, ликвидация или банкротство не являются угрозой для дальнейшего развития кластера.

От компаний, входящих в ядро кластера зависит специализация вида экономической деятельности данного кластера. В исследованиях кластера для определения деятельности кластера могут применяться следующие стандарты классификации видов деятельности: ОКВЭД 2, NACE, NAICS) [10].

Состав организаций, входящих в ядро кластера, индивидуален. Для кластера, связанного с разработкой новых химических соединений - наличие специализированного ВУЗа в числе участников кластера необходимо, а для иного кластера нет, так как он заказывает необходимые исследования у неограниченного количества ВУЗов. Участники кластера взаимодействуют между собой, а также с экономическими агента- ми за пределами кластера. Следует признать, что кластер не может функционировать без наличия внешних потребителей продукции, работ и услуг кластера и его участников.

Участники кластера имеют возможность реализовывать совместные и/или самостоятельные (независимые) проекты. Автономия участников кластера дает им возможность действовать на рынке в качестве самостоятельных субъектов, а также пользоваться синергетическим эффектом, полученным в результате кластерной интеграции. Кластерная и внутри кластерная конкуренция дает основу для появления необходимой динамики развития инноваций и создания новых рабочих мест [8].

Участники кластера, будучи независимыми, взаимодействуют между собой, образуя кластер, а также взаимодействуют с внешними по отношению к кластеру экономическими агентами. Появляется потребность финансирования операционной и инвестиционной деятельности:

- кластера;

- участников кластера;

- управляющей компании или специализированной организации кластера.

На рисунке 2 представлена структура источников финансирования операционной и инвестиционной деятельности кластера и участников кластера.

Традиционно источники финансирования юридического лица разделяют на три типа:

- собственные источники финансирования;

- заемные источники финансирования;

- привлеченные источники финансирования.

Автор не ограничивает состав каждого источника финансирования. Внутренними средствами для хозяйствующего субъекта являются собственные источники финансирования, в то время как заемные и привлеченные источники - внешние источники финансирования. Каждый участник кластера функционирует как независимое юридическое лицо и, следовательно, самостоятельно принимает решение о привлечении источника финансирования. Все источники финансирования операционной и ин- 
вестиционной деятельности участников кластера подразделяются:

I. Собственные средства участника кластера:

- чистая прибыль;

- резервные фонды;

- амортизационные отчисления и т.д.
II. Заемные средства участника кластера

- банковский кредит;

- коммерческий кредит;

- средства от выпуска долговых ценных бумаг;

- краудлендинг;

- краудинвестинг и т.д.

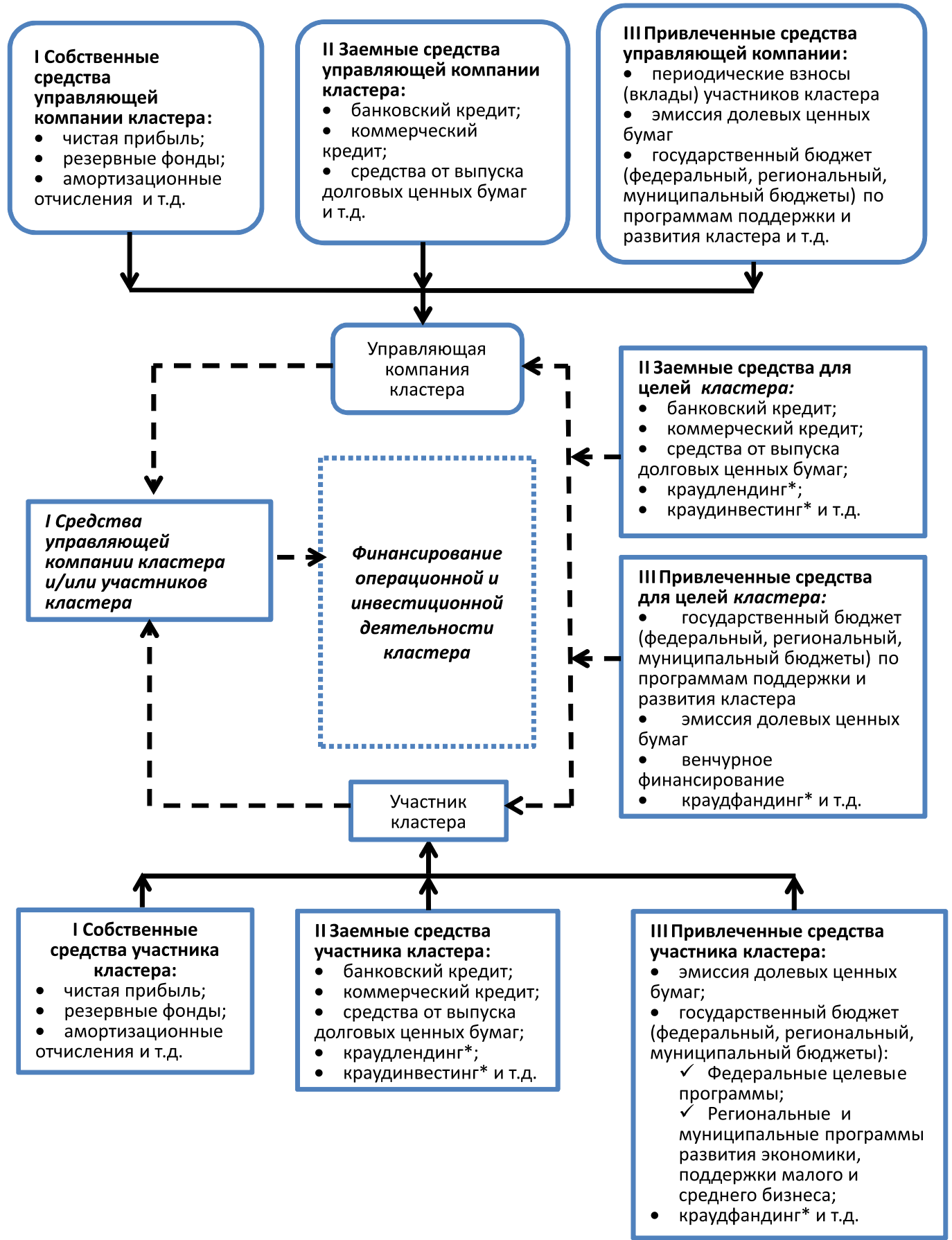

Рис. 2. Структура источников финансирования операционной и инвестиционной деятельности кластера и его участников. Источник: автор на основе [40], [27], [18], [19].

*Альтернативные источники финансирования (краудфандинг, краудинвестинг, краудлендинг) 
III. Привлеченные средства участника кластера:

- эмиссия долевых ценных бумаг;

- государственные бюджет (федеральный, региональный, муниципальный бюджеты):

- Федеральные целевые программы;

- Региональные и муниципальные программы развития экономики, поддержки малого и среднего бизнеса;

- краудфандинг и т.д.

Учредители управляющей компании кластера принимают решение о способах финансирования операционной и инвестиционной деятельности. Можно выделить следующую классификацию источников финансирования операционной и инвестиционной деятельности управляющей компании кластера:

I. Собственные средства управляющей компании кластера:

- чистая прибыль;

- резервный фонд;

- амортизационные отчисления и т.д.

II. Заемные средства управляющей компании кластера:

- банковский кредит;

- коммерческий кредит;

- средства от выпуска долговых ценных бумаг и т.д.

III Привлеченные средства управляющей компании кластера:

- периодические взносы (вклады) участников кластера;

- эмиссия долевых ценных бумаг;

- государственный бюджет (федеральный, региональный, муниципальный бюджеты) по программам поддержки и развития кластера;

- краудфандинг и т.д.

Управляющая компания кластера может эмитировать или выпускать ценные бумаги, но существуют определенные ограничения, которые надо учитывать. Например, в соответствии с Федеральными законами «Об акционерных обществах» и «Об обществах с ограниченной ответственностью» облигации могут размещать только акционерные общества и общества с ограниченной ответственностью [1], [2]. Следовательно, если управляющая компания кластера не будет зарегистрирована в качестве ООО или АО, то у нее нет доступа к указанным источникам финансирования.
Существует большая финансовая зависимость деятельности управляющей компании кластера от государственного бюджета, когда она создается по инициативе государства и ее функции выполняют региональные институты развития (например, центры поддержки предпринимательства центры кластерного развития), чем для управляющих компаний кластера, которые были созданы по инициативе участников кластера.

Финансирование операционной и инвестиционной деятельности кластера направлено на аккумулирование денежных средств достаточных для осуществления совместной деятельности участников кластера и/или инвестиционных проектов кластера.

Для финансирования операционной и инвестиционной деятельности кластера требуется определить перечень возможных источников:

I. Средства участников кластера и/ или управляющей организации кластера.

II. Заемные средства для целей кластера:

- банковский кредит;

- коммерческий кредит;

- средства от выпуска долговых ценных бумаг;

- краудлендинг;

- краудинвестинг и т.д.

III. Привлеченные средства для целей кластера:

- государственный бюджет (федеральный, региональный, муниципальный бюджеты) по программам поддержки и развития кластера;

- эмиссия долевых ценных бумаг;

- венчурное финансирование;

- краудфандинг и т.д.

Следует отметить, что средства государственного бюджета (федерального, регионального, муниципального) по программам поддержки и развития кластера могут направляться на финансирование операционной и инвестиционной деятельности кластера, в том числе и финансирование управляющей компании кластера.

Для привлечения внешнего источника финансирования кластера (заемных и привлеченных средств) требуется участие управляющей компании кластера, чтобы она могла представлять интересы кластера при взаимодействии с органи- 
зациями или кто-то из участников кластера помимо управляющей компании кластера заключал соответствующие соглашения.

Россия начала реализовывать кластерную программу позже, чем например США или ЕС. Следует отметить, что проведенные исследования реализации кластерных программ других стран показывает, что доля государственного финансирования кластеров составляет 60\% [7].

Кластер и участники кластера могут применять для финансирования своей операционной и инвестиционной деятельности альтернативные источники финансирования («crowd financing» краудфинансирование) - краудфандинг, краудинвестинг, краудлендинг.

Краудфандинг - это массовая народная форма финансирования, с целью поддержания творческих проектов, стартапов, бизнеса, а также благотворительных акций по средствам различные интернет платформ [25].

В отличие от краудфандинга краудинвестинг - это разновидность коллективного инвестирования, основной целью которого является получение части прибыли от финансируемой компании или определенного доли акций [23].

Краудлендинг - кредитование физическими лицами других физических лиц или компаний через онлайн-площадки с применением кредитно-финансовых инструментов проверки вкладчиков и заемщиков [24].

Примеры площадок, позволяющих привлекать краудфинансирование:

- краудфандинг - Kickstarter. com, Boomstarter.ru;

- краудинвестинг - Crowdcube.com, Starttrack.ru;

- краудлендинг - Lendingclub.com, investor.potok.digital.

Альтернативные источники финансирования становятся все более актуальными для российских компаний. Представленные альтернативные формы финансирования характеризуются рядом преимуществ, по сравнению с традиционными источниками финансирования (банковское кредитование, фондовый рынок и т.д.):

- обеспечивают бесплатную рекламу;

- позволяют оценить уровень спроса и уменьшить риски;
- нет зависимости от банков, так как происходит сбор коллективных средств от лиц, заинтересованных в реализации проекта [29];

- позволяют привлекать больше заинтересованных сторон - физических и юридических лиц, резидентов и нерезидентов;

- круглосуточная работа и высокая скорость информирования заинтересованных сторон через специализированную платформу, а также возможность привлечения социальных сетей, в отличие от фиксированного периода работы банков, фондовых бирж и т.д.;

Для рассматриваемых в статье альтернативных источников финансирования существует следующие общие признаки:

- основные виды взаимодействия: Р2P (физическое лицо - физическое лицо); Р2В (физическое лицо - компания); В2В (компания-компания);

- использование цифровых технологий и специализированных платформ [23];

- необходимость выплаты комиссии, как специализированной платформе, так и специализированным сервисам [34]. Тем не менее, несмотря на комиссию, альтернативные формы финансирования «дешевле» относительно традиционных источников финансирования (банковский кредит, фондовый рынок и т.д.);

- правительства многих стран уже приняли или планируют принятие законов, регулирующих крауд-технологии финансирования, предписывающих требования к специализированным площадкам и их участникам. Например, в США и Израиле законодательно регулируется краудфандинг [31]. В России также принимаются законодательные акты, регулирующие работу инвестиционных платформ, информационных систем, осуществляющих выпуск цифровых финансовых активов, цифровой валюте и вносятся изменения в существующие законы с целью актуализировать их с акцентом на цифровую экономику. Принят Ф3 «О привлечении инвестиций с использованием инвестиционных платформ и о внесении изменений в отдельные законодательные акты Российской Федерации» [2].

Федеральный закон «О цифровых финансовых активах, цифровой валю- 
те и о внесении изменений в отдельные законодательные акты Российской Федерации», который вступит в силу с 01.01.2021, вводит в законодательное поле следующие понятия: «цифровые финансовые активы», «цифровая валюта» [4]. Появление данного закона позволит рассматривать возможность применения криптовалюты (цифровой валюты) и цифровых финансовых активов в качестве средств финансирования деятельности предприятий и/или кластера.

Законодательное регулирование с одной стороны повышает затраты, связанные с привлечением финансирования (вследствие ответного повышения комиссии со стороны специализированных площадок), но с другой стороны: повышается доверие к краудинговым источникам финансирования в долгосрочном периоде времени и защищает права инвесторов, кредиторов, лиц привлекающих денежные средства, специализированных платформ.

В таблице представлено сравнение альтернативных источников финансирования: краудфандинг, краудинвестинг, краудлендинг. долю в акционерном капитале компании, а также несут риск, связанный с потерей своих вложений [32]. Инвесторы могут получить часть будущей прибыли компании. При краудлендинге получатель денежных средств должен вернуть полностью привлечённую сумму денег и выплатить вознаграждение за предоставленный капитал. По сути краудлендинг является заемным источником финансирования деятельности кластера и участника кластера.

Суть деятельности кластера заключается в независимости участников кластера и взаимодействие участников кластера на основе конкуренции. Следовательно, при финансировании кластера главное не допустить ситуации появления чрезмерного количества зависимых и дочерних обществ с целью сохранения конкуренции между участниками кластера.

Существует возможность повышения риска участника кластера, так как помимо осуществления своей операционной и инвестиционной деятельности ему придется выполнять определенные обязательства по участию в операци-

Сравнение альтернативных источников финансирования: краудфандинг, краудинвестинг, краудлендинг*

\begin{tabular}{|c|c|c|c|}
\hline Критерии & Краудфандинг & Краудинвестинг & Краудлендинг \\
\hline Цель & $\begin{array}{c}\text { Финансирование } \\
\text { инновационных } \\
\text { (венчурных) проектов }\end{array}$ & $\begin{array}{c}\text { Финансирование инновационных } \\
\text { (венчурных) проектов }\end{array}$ & $\begin{array}{c}\text { Финансирование теку- } \\
\text { щей и инвестиционой } \\
\text { деятельности не инно- } \\
\text { вационных компаний }\end{array}$ \\
\hline $\begin{array}{c}\text { Возврат привле- } \\
\text { ченных средств }\end{array}$ & Нет & Да, но возврат не гарантирован & Да \\
\hline $\begin{array}{c}\text { Плата за пользо- } \\
\text { вание привлечен- } \\
\text { ными средствами }\end{array}$ & Нет & $\begin{array}{c}\text { Да, в виде прибыли } \\
\text { от деятельности компании }\end{array}$ & Да \\
\hline
\end{tabular}

*Источник: автор, на основе [23], [24], [29], [32], [35].

Для финансирования инновационных (венчурных) проектов больше всего подходит краудфандинг и краудинвестинг, для финансирования текущей и инвестиционной деятельности, но не связанной с инновациями приемлем краудлендинг.

Лица, предоставившие денежные средства на основе краудфандинга, не преследуют цели получения прибыли и возврата своих средств. В случае краудинвестинга инвесторы получают онной и инвестиционной деятельности кластера. Управление рисками участников кластера и кластера в целом является достаточно актуальным для исследований [9], [10], [22], [26].

\section{Заключение}

Конкурентоспособность кластера отчасти зависит от достаточности финансирования его операционной и инвестиционной деятельности. Участни- 
ки кластера, будучи самостоятельными юридическими лица конкурируют между собой, но в тоже время, взаимодействуют в кластере. Субъектами кластера являются участники кластера и управляющая компания или специализированная организация кластера. Следует отметить, что с целью формализации кластера, организации кооперационных связей участников кластера и представления их интересов в России является обязательным создание управляющей компании кластера.

Кластер является формой сетевого взаимодействия участников кластера. Появляется потребность финансирования операционной и инвестиционной деятельности:

- кластера;

- участников кластера;

- управляющей компании или специализированной организации кластера.

Управляющая компания кластера и участники кластера в качестве самостоятельных юридических лиц самостоятельно принимают решения об источниках финансирования своей операционной и инвестиционной деятельности. Ряд источников для управляющей компании кластера и участников кластера совпадают:

I. собственные средства (чистая прибыль; резервные фонды; амортизационные отчисления и т.д.);

II. заемные средства (банковский кредит; коммерческий кредит; средства от выпуска долговых ценных бумаг; краудлендинг; краудинвестинг и т.д.).

Эмиссия долевых ценных бумаг возможна как для финансирования участников кластера, управляющей компании кластера, так и для финансирования операционной и инвестиционной деятельности кластера. Однако существуют определенные ограничения по эмиссии долевых ценных и выпуску долговых ценных бумаг, которые необходимо соблюдать с точки зрения законодательства, а также положений бирж - условия по организационно-правовой форме юридического лица, составу органов управления, уставному капиталу и т.д.

Средства государственного бюджета (федерального, регионального, муниципального бюджетов) по программам поддержки и развития кластера могут направляться как на финансирование операционной и инвестиционной деятельности кластера, так и являться привлеченными средствами для управляющей компании кластера. Также участник кластера, независимо от деятельности кластера может получать средства государственного бюджета (федерального, регионального, муниципального бюджетов) в пределах:

- Федеральных целевых программ;

- Региональных и муниципальных программ развития экономики, поддержки малого и среднего бизнеса.

Периодические взносы (вклады) участников кластера являются привлеченными средствами для управляющей компании кластера.

Для финансирования кластера и его участников возможно применение альтернативных источников финансирования: краудфандинг, краудинвестинг, краудлендинг. В России разрабатываются и вступают в силу законы, регулирующие способы финансирования на основе цифровых технологий, а также краудфинансирования. Государственное регулирование привлечения инвестиций с применением инвестиционных платформ повышает доверие к краудинговым источникам финансирования в долгосрочном периоде времени и защищает права инвесторов, кредиторов, лиц привлекающих денежные средства.

Новые федеральные законы, регулирующие вопросы использования инвестиционных платформ, цифровых финансовых активов, криптовалюты, позволяют рассматривать возможность применения новых источников и средств финансирования - краудфандинга, криптовалюты и цифровых финансовых активов, что даст возможность увеличить финансирование деятельности кластера и его участников.

\section{Библиографический список}

1. Федеральный закон от 08.02.1998 N 14-Ф3 (ред. от 04.11.2019, с изм. от 31.07.2020) «Об обществах с ограниченной ответственностью» // Консультант Плюс: [официальный сайт]. URL: http:// www.consultant.ru/document/cons doc LAW 17819/ (дата обращения: 01.07.2020). 
2. Федеральный закон от 02.08.2019 N 259-Ф3 (ред. от 20.07.2020) «О привлечении инвестиций с использованием инвестиционных платформ и о внесении изменений в отдельные законодательные акты Российской Федерации»// Консультант Плюс: [официальный сайт]. URL: http://www.consultant. ru/document/cons_doc_LAW_330652/(дата обращения: 03.08.2020).

3. Федеральный закон от 26.12.1995 N 208-ФЗ (ред. от 31.07.2020) «Об акционерных обществах» // Консультант Плюс: [официальный сайт]. URL: http://www.consultant.ru/document/cons_doc_ LAW_8743/ (дата обращения: 02.07.2020) . Федеральный закон от 31.07.2020 N 259-Ф3 «О цифровых финансовых активах, цифровой валюте и о внесении изменений в отдельные законодательные акты Российской Федерации» // Консультант Плюс: [официальный сайт]. URL: http://www.consultant.ru/ document/cons_doc_LAW_358753/(дата обращения: 05.08.2020).

4. Постановление правительства РФ от 31.07.2015 n 779 (ред. от 02.08.2018) «О промышленных кластерах и специализированных организациях промышленных кластеров» // Кодификация РФ: [официальный сайт]. URL: https://rulaws.ru/goverment/Postanovlenie-Pravitelstva-RF-ot-31.07.2015-N-779/ (дата обращения: 25.07.2020) .

5. Распоряжение Правительства РФ от 17.11.2008 N 1662-р (ред. от 28.09.2018) «О Концепции долгосрочного социально-экономического развития Российской Федерации на период до 2020 года» (вместе с «Концепцией долгосрочного социально-экономического развития Российской Федерации на период до 2020 года») // Консультант Плюс: [официальный сайт]. URL: http://www.consultant. ru/document/cons_doc_LAW_82134/28c7f9e359e8af09d7244d8033c66928fa27e527/ (дата обращения: 26.07.2020)

6. Lindqvist G., Ketels C., Sölvell Ö. The Cluster Initiative Greenbook 2.0, Stockholm: Ivory Tower Publishers, 2013.

7. Агарков А.П. Проектирование и формирование инновационных промышленных кластеров: монография / Агарков А.П., Голов Р.С. Москва: Дашков и К, 2016. 288 с.

8. ИзмаЛКова И. В. УПРАВЛЕНИЕ РИСКАМИ ПРЕДПРИЯТИЙ КЛАСТЕРНЫХ СТРУКТУР: диссертация ... кандидата экономических наук: 08.00.05. Курск, 2019. 211 с.

9. Стрельник М.М. Методы управления и оценки рисков предприятий в условиях кластера: монография. СПб: Изд-во Санкт-Петербургского государственного экономического университета, 2018. $151 \mathrm{c}$.

10. Кравцова И. В. Проблема сокращения коммерческих банков в Российской Федерации: причины и последствия // Менеджер. 2018. № 2 (84). С. 158-164.

11. Бондарчук О.П., Бешкок Е.А. Анализ банковского сектора РФ в современных условиях // Аллея науки. 2017. Т. 1. № 15. С. 39-43.

12. Боуш Г.Д. Компонентно-элементный состав бизнес-кластеров: системное представление // Вестник Новосибирского государственного университета. Серия: Социально-экономические науки. 2010. T. 10. № 4. C. 62-73.

13. Водопьянова А.Н. Проблемы финансовой стабилизации российских предприятий в условиях западных санкций // Science Time. 2015. № 4 (16). С. 122-128.

14. Екимова К.В., Федина Е.В. Об особенностях финансирования процессов образования региональных кластеров // Вестник Российского экономического университета имени Г.В. Плеханова. 2013. № 8 (62). C. 66-69.

15. Костенко О.В. Кластер как объект управления и социально-экономическая система // Аграрная наука Евро-Северо-Востока. 2015. № 6 (49). С. 75-80.

16. Костенко О.В. Управляющие компании кластеров: российский и зарубежный опыт // Фундаментальные исследования. 2017. № 10-3. С. 594-599.

17. Масленников М.И., Брыков С.С. Финансовый инструментарий развития и управления кластерами в регионах России // Вестник Южно-Уральского государственного университета. Серия: Экономика и менеджмент. 2016. Т. 10. № 1. С. 39-50.

18. Миляев К.В. Венчурное финансирование инновационных проектов в агропромышленном производстве в бизнес-акселераторах: кластерный подход // Международный научно-исследовательский журнал. 2016. № 12-5 (54). С. 175-178.

19. Сайбель Н.Ю., Ковальчук А.В. Фондовый рынок россии: проблемы и перспективы развития // Финансы и кредит. 2018. Т. 24. № 3 (771). С. 613-626.

20. Стрельник М.М. Классификация промышленных кластеров // Экономика и предпринимательство. 2017. № 3-1 (80). С. 852-857.

21. Стрельник М.М., Тишков П.И. Управление рисками предприятия в условиях кластера // Coвременные проблемы науки и образования. 2014. № 6. Режим доступа: https://science-education.ru/ru/ article/view?id=15367 (дата обращения: 16.07.2020).

22. Суворов Н.С. Краудное финансирование как альтернативный источник финансового обеспечения предприятий малого бизнеса // Вестник Воронежского государственного университета инженерных технологий. 2016. № 3 (69). С. 401-403. 
23. Сумкина О.В., Мокина Л.С. Краудлендинг как инструмент альтернативного финансирования: российский опыт // Молодежь и XXI век - 2017: материалы VII Международной молодежной научной конференции, Курск, 21-22 февр. 2017. Курск: УрГЭУ, 2017. Т. 1. С. 292-297.

24. Тегин В., Усманов Б. Краудфандинг как стратегия инвестирования в инновации // Мир транспорта. 2014. № 4 (53). С. 98-106.

25. Узбекова А.С., Плеханова А.Ф., Шибанов Н.А. Риски кластерных образований и их субъектов // Вестник Нижегородского университета им. Н.И. Лобачевского. Серия: Социальные науки. 2015. № 3 (39). С. 70-76.

26. Хмурова Т.В., Джуджуев М.Ф., Езангина И.А. Роль коммерческих банков в финансировании инновационных кластеров в России // Управление. Бизнес. Власть. 2016. № 2 (11). С. 72-76.

27. Чекаданова М.В. Задачи и механизмы деятельности органов управления кластером по обеспечению его эффективной работы // МИР (Модернизация. Инновации. Развитие). 2018. Т. 9. № 2. C. 232-247.

28. Чуланова О.Л. Современные крауд - технологии: краудсорсинг, краудфандинг, краудинвестинг, краудлендинг // Материалы Афанасьевских чтений. 2017. № 1 (18). С. 64-79.

29. Шендрикова О.О., Вандышева С.В., Луценко М.С. Промышленный кластер: организационный и управленческий аспекты // Известия Юго-Западного государственного университета. Серия: Экономика. Социология. Менеджмент. 2017. Т. 7. № 3 (24). С. 98-106.

30. «Краудфандинг в законе»: настоящее и будущее регулирования краудфандинговых кампаний. Текст: электронный // ForkLog - медиакомпания в сфере криптовалют и блокчейна: [сайт]. URL: https://forklog.com/kraudfanding-v-zakone-nastoyashhee-i-budushhee-regulirovaniya-kraudfandingovyhkampanij/ (дата обращения: 01.08.2020).

31. Stop Calling It Crowdfunding. Текст: электронный // Crowdfund Insider: [сайт]. URL: https:// www.crowdfundinsider.com/2013/04/14073-crowdinvesting-stop-calling-it-crowdfunding/ (дата обращения: 28.07.2020).

32. Карта кластеров России. Текст: электронный // Российская кластерная обсерватория: [сайт]. URL: http://map.cluster.hse.ru/list (дата обращения: 30.07.2020).

33. Краудинвестинг и краудлендинг: авантюра или инвестиция? Текст: электронный // Проект «Ваш Казначей»: [сайт]. URL: https://vashkaznachei.ru/kraudinvesting-i-kraudlending-avant/ (дата обращения: 03.08.2020).

34. Краудфандинг и краудинвестинг - что это такое простыми словами: виды и особенности + зарубежные и российские краудфандинговые площадки. Текст: электронный // Richpro - финансовый журнал: [сайт]. URL: https://richpro.ru/stati/kraudfanding-chto-eto-takoe-kraudinvesting-rossijskieploshhadki-crowdfunding.html (дата обращения: 03.08.2020).

35. Минэкономразвития в 2016 году расширит программу поддержки территориальных инновационных кластеров. Текст: электронный // Министерство экономического развития Российской Федерации: [официальный сайт]. URL: http://economy.gov.ru/minec/about/structure/depIno/20160220 (дата обращения: 29.07.2020).

36. О проекте перечня пилотных программ развития инновационных территориальных кластеров. Текст: электронный // Министерство экономического развития Российской Федерации: [официальный сайт]. URL: http://economy.gov.ru/wps/wcm/connect/1a5dcd004bf64bef858d9d77bb90350d/ doklad proekt.pdf?MOD=AJPERES (дата обращения: 26.07.2020).

37. Правительство может сократить расходы на нацпроекты, стройки и инвестиции. Текст: электронный // Ведомости: [сайт]. URL: https://www.vedomosti.ru/economics/articles/2020/03/23/826004pravitelstvo-sokratit (дата обращения: 28.07.2020).

38. Россия в цифрах 2020. Краткий статистический сборник. Текст: электронный // Федеральная служба государственной статистики: [официальный сайт]. URL: https:/www.gks.ru/storage/mediabank/ GOyirKPV/Rus_2020.pdf (дата обращения: 02.08.2020).

39. Трансформация модели финансирования кластеров в России: [презентация: Апрельская конференция НИУ ВШЭ, 2018] / Абашкин В., Куценко Е., Исланкина Е. Текст: электронный // Высшая школа экономики (НИУ ВШЭ): [официальный сайт]. https://www.hse.ru/mirror/pubs/ share/218579616 (дата обращения: 23.07.2020). 